\title{
A Minimum Coprime Number for Amalgamation of Wheel
}

\author{
Hafif Komarullah ${ }^{1, *}$, Slamin $^{2}$, Kristiana Wijaya ${ }^{1}$ \\ ${ }^{1}$ Graph, Combinatorics, and Algebra Research Group, Department of Mathematics, FMIPA, Universitas Jember \\ ${ }^{2}$ Study Program of Informatics, Universitas Jember, Indonesia \\ *Corresponding author. Email: hafififa4@gmail.com
}

\begin{abstract}
Let $G$ be a simple graph of order $n$. A coprime labeling of a graph $G$ is a vertex labeling of $G$ with distinct positive integers from the set $\{1,2, \ldots, k\}$ for some $k \geq n$ such that any adjacent labels are relatively prime. The minimum value of $k$ for which $G$ has a coprime labelling, denoted as $\operatorname{pr}(G)$, is called the minimum coprime number of $G$. A coprime labeling of $G$ with the largest label being $\operatorname{pr}(G)$ is said a minimum coprime labeling of $G$. In this paper, we give the exact value of the minimum coprime number for amalgamations of wheel $W_{n}$ when $n$ is odd positive integer.
\end{abstract}

Keywords: Minimum coprime labeling, Minimum coprime number, Amalgamation of wheel.

\section{INTRODUCTION}

Let $G$ be a simple graph with the vertex-set $V(G)$ and the edge-set $E(G)$. A coprime labeling of a graph $G$ is an injective function $f: V(G) \rightarrow\{1,2, \ldots, k\}$ so that the labels of any two adjacent vertices are relatively prime. Clearly that $k \geq n$, where $n$ is the number of vertices of a graph $G$. If $k=n$, then the function $f$ is called a prime labeling of $G$. A graph that admits a prime labelling is called a prime. However, it does not make sense to refer to a graph as coprime, since all graphs have a coprime labeling (for instance, use the first $n$ prime integers as the labels) (see [1]). Therefore, the problem of a coprime labeling is to find the minimum value of $k$ namely a minimum coprime number of $G$ and denoted as $\mathfrak{p r}(G)$. A coprime labeling of $G$ with the largest label being $\operatorname{pr}(G)$ is said a minimum coprime labeling of $G$.

The concept of a prime labeling originated with Entringer and was first introduced in a paper by Tout, Dabbouvy, and Howalla [2]. Around 1980, Entringer gave conjecture that all trees are prime graphs. Among the classes of trees known as prime are paths, stars, spiders, olive trees, palm trees, binomial trees, all trees of order up to 50, banana trees, and all caterpillars with maximum degree at most 5 (see $[2,3,4,5,6,7])$.

Deretsky, Lee, and Mitchem [8] proved that all cycles $C_{n}$ (i.e., a 2 -regular graph with $n$ vertices) are prime. Lee, Wui, and Yeh [9] proved that wheel $W_{n}$ (i.e., a cycle
$C_{n}$ with one central vertex adjacent to $n$ vertices in $C_{n}$ ) is prime if and only if $n$ is even; a complete graph $K_{n}$ (i.e., an $(n-1)$-regular graph with $n$ vertices) is not prime for $n \geq 4$. The other results about prime labeling can be seen in $[10,11,12,13,14,15,16]$ and completely the survey about this labeling in Galian [17].

Asplund and Fox [18] obtained the exact value of the minimum coprime number of complete graph $K_{n}$ and odd wheel $W_{n}$ (i.e., wheel $W_{n}$ with odd $n$ ) namely $\operatorname{pr}\left(K_{n}\right)=$ $p_{n-1}$, where $p_{n-1}$ is the first $(n-1)$ primes; and $\operatorname{pr}\left(W_{n}\right)=n+2$ for any odd integer $n \geq 3$. In another paper, Asplund and Fox [19] gave the minimun coprime number of Generalized Petersen and Prism Graphs. Lee [20] determine the minimum coprime number for a few well-studied classes of graphs, including the coronas of complete graphs with empty graphs and the joins of two paths.

Herein, we discuss about the minimum coprime labeling for amalgamation of wheel. Amalgamation of $t$ copies of $G$ at the fixed vertex $v_{0} \in V(G)$, denoted by $\operatorname{Amal}\left(G, v_{0}, t\right)$, is the graph obtained from $t$ copies of $G$ by identifying $t$ copies of $G$ at the fixed vertex $v_{0}$. Lee, Wui, and Yeh [11] have shown that $\operatorname{Amal}\left(G, v_{0}, t\right)$ has a prime labeling when $G$ is a path, a cycle, or an even wheel. They also showed that the amalgamation of odd wheel is not prime. Therefore, in this paper we give the the exact value of the minimum coprime number of 
$\operatorname{Amal}\left(W_{n}, v_{0}, t\right)$ when $n$ is odd and $v_{0}$ is the central vertex of wheel $W_{n}$, namely the vertex of degree $n$ in $W_{n}$.

\section{MAIN RESULTS}

In this section we will discuss prime and coprime labeling for amalgamation of wheel $W_{n}$ for any odd positive integer. Before doing that, we discuss about two integers said to be relatively prime. We know that $\operatorname{gcd}(a, 1)=1$ for any integer $a$. Any two consecutive integers also has the greatest common divisor one, namely $\operatorname{gcd}(a, a+1)=1$. Two lemmas below useful to prove that two integers are relatively prime.

Theorem 2.1 [21] Two integers $a$ and $b$ are said to be relatively prime, if there exist two integers $x$ and $y$ such that $a x+b y=1$.

Lemma 2.2 Let $a$ be odd positive integer. If a positive integer $r$ does not have odd factor other than one, then $\operatorname{gcd}(a, a+r)=1$.

Proof. Suppose that $\operatorname{gcd}(a, a+r)=k$. Then $a=k x$ and $a+r=k y$. So $k(y-x)=r$. Both $a$ and $a+r$ are odd. So, $k$ must be odd. Since $r$ does not have odd factor other than one, we get $k=1$. Therefore $\operatorname{gcd}(a, a+r)=1$.

Let $v_{0}$ be the central vertex of wheel $W_{n}$. Suppose the vertex-set and edge-set of an $\operatorname{Amal}\left(W_{n}, v_{0}, t\right)$ are $V\left(\operatorname{Amal}\left(W_{n}, v_{0}, t\right)\right)=\left\{v_{0}\right\} \cup\left\{v_{i j} \mid i \in[1, t], j \in[1, n]\right\}$, where degree of $v_{0}$ and $v_{i j}$ is $d\left(v_{0}\right)=n t$ and $d\left(v_{i j}\right)=$ 3, respectively, and $E\left(\operatorname{Amal}\left(W_{n}, v_{0}, t\right)\right)=$ $\left\{v_{0} v_{i j}, v_{i 1} v_{i n} \mid i \in[1, t], j \in[1, n]\right\} \cup\left\{v_{i j} v_{i j+1} \mid i \in\right.$ $[1, t], j \in[1, n-1]\}$, respectively. An $\operatorname{Amal}\left(W_{n}, v_{0}, t\right)$ has $(n t+1)$ vertices. The lower bound of the minimum coprime number for amalgamation of the odd wheel is given in Lemma below.

Lemma 2.3 Let $v_{0}$ be the central vertex of wheel $W_{n}$. For each integer $t>1$ and odd integer $n \geq 1$, $\operatorname{pr}\left(\operatorname{Amal}\left(W_{n}, v_{0}, t\right)\right) \geq(n+1) t+1$.

Proof. Let $n, t \geq 1$ be integers where $n$ is odd. We know that an $\operatorname{Amal}\left(W_{n}, v_{0}, t\right)$ has $(n t+1)$ vertices, where the one vertex, called the central vertex $v_{0}$ adjacent to all vertices in $\operatorname{Amal}\left(W_{n}, v_{0}, t\right)$. There are $t$ cycles with length $n$ where every cycle needs $\frac{n-1}{2}$ even labels and $\frac{n+1}{2}$ odd labels. So, a graph $\operatorname{Amal}\left(W_{n}, v_{0}, t\right)$ needs $\left(\left(\frac{n+1}{2}\right) t+1\right)$ odd labels. Clearly that there are not enough odd labels in the set $\{1,2, \ldots, n t+1\}$. It means that an $\operatorname{Amal}\left(W_{n}, v_{0}, t\right)$ cannot be labeled by $1,2, \ldots, n t+1$ such that every two adjacent vertices have the relatively prime labels. Since there are $\left(\left(\frac{n+1}{2}\right) t+1\right)$ odd labels in the set $\{1,2, \ldots,(n+1) t+1\}$, hence $\operatorname{pr}\left(\operatorname{Amal}\left(W_{5}, v_{0}, t\right)\right) \geq(n+1) t+1$.
To obtain the exactly of the minimum coprime number for amalgamation of odd wheel $W_{n}$, we consider two cases, namely for either $n=1(\bmod 4)$ or $n=$ $3(\bmod 4)$.

Theorem 2.4 Let $v_{0}$ be the central vertex of wheel $W_{n}$. For each integer $t>1$ and $n=1(\bmod 4)$, the minimum coprime number for amalgamation of odd wheel $W_{n}$ is $\operatorname{pr}\left(\operatorname{Amal}\left(W_{n}, v_{0}, t\right)\right)=(n+1) t+1$.

Proof. Let $n$ and $t$ be positive integers where $n=$ $1(\bmod 4) . \quad$ By Lemma 2.3, we have $\operatorname{pr}\left(\operatorname{Amal}\left(W_{n}, v_{0}, t\right)\right) \geq(n+1) t+1$.

We now show that $\operatorname{pr}\left(\operatorname{Amal}\left(W_{n}, v_{0}, t\right)\right) \leq(n+$ 1) $t+1$ by defined a coprime labeling of a graph $\operatorname{Amal}\left(W_{n}, v_{0}, t\right)$ as below. We define $f: V\left(\operatorname{Amal}\left(W_{n}, v_{0}, t\right)\right) \rightarrow\{1,2, \ldots,(n+1) t+1\}$ where $f\left(v_{0}\right)=1$ and for $i=1,2, \ldots, t$, $f\left(v_{i j}\right)=\left\{\begin{array}{c}(n+1) i-(n-j), \text { for } 1 \leq j \leq \frac{n+1}{2}, \\ (n+1) i+1, \text { for } j=\frac{n+3}{2}, \\ (n+1) i+\left(\frac{n+3}{2}-j\right), \text { for } \frac{n+5}{2} \leq j \leq n .\end{array}\right.$

Next, we show that the greatest common divisor of every labels of two adjacent vertices are one. We consider three cases below.

- Suppose that $\operatorname{gcd}\left(f\left(v_{i\left(\frac{n+1}{2}\right)}\right), f\left(v_{i\left(\frac{n+3}{2}\right)}\right)\right)=$ $\operatorname{gcd}\left((n+1) i-\left(\frac{n-1}{2}\right),(n+1) i+1\right)=k . \quad$ Since $n=1(\bmod 4), \quad$ then $\quad(n+1) i-\left(\frac{n-1}{2}\right)=$ $1\left(\bmod \left(\frac{n+1}{2}\right)\right)$ is even, while $(n+1) i+1=$ $1\left(\bmod \left(\frac{n+1}{2}\right)\right)$ is odd. So $k \neq \frac{n+1}{2}$ must be odd. Let $(n+1) i-\left(\frac{n-1}{2}\right)=k x$ and $(n+1) i+1=k y$. Then $k(y-x)=\frac{n+1}{2}$. So it must be $k=1$. Therefore labels of $v_{i\left(\frac{n+1}{2}\right)}$ and $v_{i\left(\frac{n+3}{2}\right)}$ are relatively prime.

- Now, consider the labels of vertex $v_{i\left(\frac{n+3}{2}\right)}$ and $v_{i\left(\frac{n+5}{2}\right)}$. Suppose that $\operatorname{gcd}\left(f\left(v_{i\left(\frac{n+3}{2}\right)}\right), f\left(v_{i\left(\frac{n+3}{2}\right)}\right)\right)=$ $\operatorname{gcd}((n+1) i+1,(n+1) i-1)=k$. Since $n$ is odd, $(n+1) i+1$ is odd. By applying Lemma 2.2, we get $\operatorname{gcd}((n+1) i+1,(n+1) i-1)=1$.

- Last, we consider the vertex $v_{i 1}$ and $v_{i n}$. We suppose that $\operatorname{gcd}\left(f\left(v_{i 1}\right), f\left(v_{i n}\right)\right)=\operatorname{gcd}((n+1) i-(n-$ $\left.1),(n+1) i+\left(\frac{3-n}{2}\right)\right)=k$. Since $n=1(\bmod 4)$, $(n+1) i-(n-1)$ is even, and $(n+1) i+\left(\frac{3-n}{2}\right)$ is odd, but both are in $2\left(\bmod \left(\frac{n+1}{2}\right)\right)$. Hence $k \neq \frac{n+1}{2}$ must be odd. We next consider $(n+1) i-(n-1)=$ 
$k x$ and $(n+1) i+\left(\frac{3-n}{2}\right)=k y$. So, $k(y-x)=\frac{n+1}{2}$. Therefore $k=1$. It means $v_{i 1}$ and $v_{i n}$ have relatively prime labels.

We have shown that every label of two adjacent vertices is relatively prime. Therefore, the function $f$ is a minimum coprime labeling with the largest label being $\operatorname{pr}\left(\operatorname{Amal}\left(W_{n}, v_{0}, t\right)\right)=(n+1) t+1$.

For example, a minimum coprime labeling of $\operatorname{Amal}\left(W_{5}, v_{0}, 4\right)$ can be seen in Figure 1, where $\operatorname{pr}\left(\operatorname{Amal}\left(W_{5}, v_{0}, 4\right)\right)=25$.

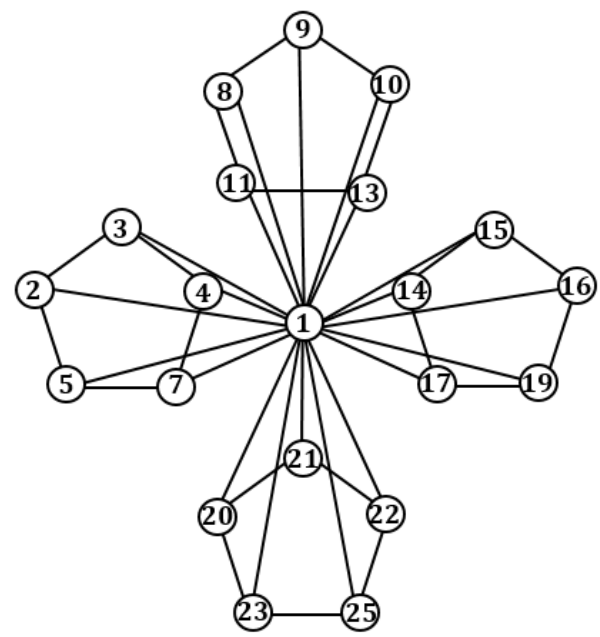

Figure 1 A coprime labelling of $\operatorname{Amal}\left(W_{5}, v_{0}, 4\right)$

We observe now an $\operatorname{Amal}\left(W_{n}, v_{0}, t\right)$ for $n=3(\bmod 4)$. For this case, we have not got the minimum coprime labeling in general. Therefore, we give it for some positive integer $n$.

Proposition 2.5 Let $v_{0}$ be the central vertex of wheel $W_{3}$. The minimum coprime number for amalgamation of $W_{3}$ is $\operatorname{pr}\left(\operatorname{Amal}\left(W_{3}, v_{0}, t\right)\right)=4 t+1$, for any positive integer $t$.

Proof. According to Lemma 2.3, we left prove that $\operatorname{pr}\left(\operatorname{Amal}\left(W_{3}, v_{0}, t\right)\right) \geq 4 t+1$, by defining a labeling on the $\operatorname{Amal}\left(W_{3}, v_{0}, t\right)$. Define $f: V\left(\operatorname{Amal}\left(W_{3}, v_{0}, t\right)\right)$ $\rightarrow\{1,2, \ldots, 4 t+1\}$ where $f\left(v_{0}\right)=1$ and for $i=$ $1,2, \ldots, t$,

$$
f\left(v_{i j}\right)= \begin{cases}2 i, & \text { for } j=1, \\ 4 i-1, & \text { for } j=2, \\ 4 i+1, & \text { for } j=3\end{cases}
$$

Now, we show that the greatest common divisor of every two labels of adjacent vertices is one.

- First, $\operatorname{gcd}\left(f\left(v_{i 1}\right), f\left(v_{i 2}\right)\right)=(2 i, 4 i-1)=1$, since there exists $x=2$ and $y=-1$ so that $(2 i) x+(4 i-$ 1) $y=1$ and applying Theorem 2.1 .
- Suppose $\operatorname{gcd}\left(f\left(v_{i 2}\right), f\left(v_{i 3}\right)\right)=(4 i-1,4 i+1)=$ $k$. Since $4 i-1$ is odd, and $|(4 i-1)-(4 i+1)|=$ 2 , by Lemma $2.1, \operatorname{gcd}(4 i-1,4 i+1)=1$.

- $\quad$ Suppose $\operatorname{gcd}\left(f\left(v_{i 1}\right), f\left(v_{i 3}\right)\right)=\operatorname{gcd}(2 i, 4 i+1)=k$. There exists $x=-2$ and $y=1$ so that $(2 i) x+$ $(4 i+1) y=1$. By Theorem 2.1, we get $\operatorname{gcd}(2 i, 4 i+$ 1) $=1$.

Thus every label of adjacent vertices is relatively prime. Hence the function $f$ is a minimum coprime labeling and $\operatorname{pr}\left(\operatorname{Amal}\left(W_{3}, v_{0}, t\right)\right)=4 t+1$.

Proposition 2.6 Let $v_{0}$ be the central vertex of wheel $W_{7}$. For a positive integer $t \leq 47$, an $\operatorname{Amal}\left(W_{7}, v_{0}, t\right)$ has a minimum coprime labeling with the largest label being $8 t+1$.

Proof. Let $t$ be positive integer and $t \leq 47$. Define $f: V\left(\operatorname{Amal}\left(W_{7}, v_{0}, t\right)\right) \rightarrow\{1,2, \ldots, 8 t+1\}, \quad$ where $f\left(v_{0}\right)=1$ and for $i=1,2, \ldots, 47$, we consider two cases, namely

For $i \neq 6(\bmod 7)$,

$$
f\left(v_{i j}\right)=\left\{\begin{array}{l}
8 i+j-7, \text { for } j=1,2, \ldots, 6, \\
8 i+1, \quad \text { for } j=7,
\end{array}\right.
$$

while for $i=6(\bmod 7)$,

$$
f\left(v_{i j}\right)=\left\{\begin{array}{c}
8\left(\frac{i+1}{7}\right), \text { for } j=1, \\
8 i+j-7, \text { for } j=2,3, \ldots, 6, \\
8 i+1, \text { for } j=7 .
\end{array}\right.
$$

Now, we show that the greatest common divisor of every label of two adjacent vertices are one.

- By Lemma 2.2, we obtain $\operatorname{gcd}\left(f\left(v_{i 6}\right), f\left(v_{i 7}\right)\right)=$ $(8 i-1,8 i+1)=1$.

- Now, we consider the vertex $v_{i 1}$ and $v_{i 7}$. For $i=$ $6(\bmod 7), \quad$ namely $i=6,13,20,27,34,41$ $\operatorname{gcd}\left(f\left(v_{i 1}\right), f\left(v_{i 7}\right)\right)=\operatorname{gcd}\left(8\left(\frac{i+1}{7}\right), 8 i+1\right)=1$. For $i \neq 6(\bmod 7)$, suppose for a contradiction, $\operatorname{gcd}\left(f\left(v_{i 1}\right), f\left(v_{i 7}\right)\right)=\operatorname{gcd}(8 i-6,8 i+1)=k \neq 1$. We know that $8 i-6=2(\bmod 4)$ is even and $8 i+$ $1=1(\bmod 4)$ is odd. So $k$ must be odd. Let $8 i-$ $6=k x$ and $8 i+1=k y$. We get $k(y-x)=7$. Therefore $k=7$. Consequently, $i=6(\bmod 7)$, a contradiction. Thus $\operatorname{gcd}(8 i-6,8 i+1)=1$.

- $\quad$ For $i=6(\bmod 7)$, namely $i=6,13,20,27,34,41$, we can easily count that $\operatorname{gcd}\left(f\left(v_{i 1}\right), f\left(v_{i 2}\right)\right)=$ $\operatorname{gcd}\left(8\left(\frac{i+1}{7}\right), 8 i-5\right)=1$.

Thus, every label of two adjacent vertices is relatively prime. Thus any integer $t \leq 47$, the $\operatorname{Amal}\left(W_{7}, v_{0}, t\right)$ has a minimum coprime labeling with the largest label being $\operatorname{pr}\left(\operatorname{Amal}\left(W_{7}, v_{0}, t\right)\right)=8 t+1$. 
For an illustration, a minimum coprime labeling for $\operatorname{Amal}\left(W_{3}, v_{0}, 3\right)$ and $\operatorname{Amal}\left(W_{7}, v_{0}, 6\right)$ as depicted in Figure 2 and Figure 3, respectively.

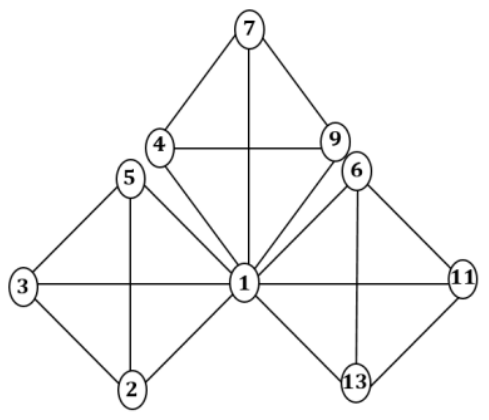

Figure 2. A coprime labeling of $\operatorname{Amal}\left(W_{3}, v_{0}, 3\right)$

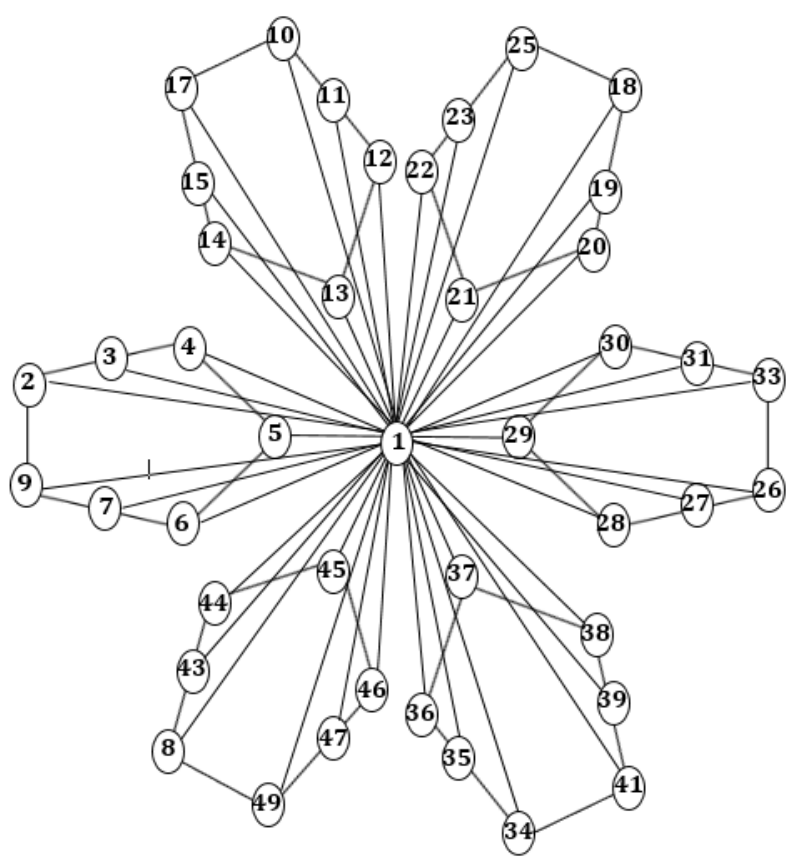

Figure 3. A coprime labeling of $\mathrm{Amal}\left(W_{7}, v_{0}, 6\right)$

Proposution 2.7 Let $v_{0}$ be the central vertex of wheel $W_{11}$. For each integer $t>1$, the minimum coprime number for amalgamation of $t$ copies of $W_{11}$ is $\operatorname{pr}\left(\operatorname{Amal}\left(W_{11}, v_{0}, t\right)\right)=12 t+1$.

Proof. According to Lemma 2.1, we left prove that $\operatorname{pr}\left(\operatorname{Amal}\left(W_{11}, v_{0}, t\right)\right) \geq 12 t+1$, by defining a labeling on the $\operatorname{Amal}\left(W_{11}, v_{0}, t\right)$. Define $f: V\left(\operatorname{Amal}\left(W_{11}, v_{0}, t\right)\right) \rightarrow\{1,2, \ldots, 12 t+1\}$ where

$f\left(v_{0}\right)=1$

$f\left(v_{i j}\right)= \begin{cases}12 i-(11-j), & \text { for } j=1,2, \ldots, 9, \\ 12 i+1, & \text { for } j=10, \\ 12 i-1, & \text { for } j=11 .\end{cases}$

Now, we show that the greatest common divisor of every label of any two adjacent vertices is one.
- Suppose that $\operatorname{gcd}\left(f\left(v_{i 9}\right), f\left(v_{i 10}\right)\right)=\operatorname{gcd}(12 i-$ $2,12 i+1)=k$. We know that $12 i-2$ is even, $12 i+1$ is odd, but both of them are in $1(\bmod 3)$. So $k \neq 3$. Let $12 i-2=k x$ and $12 i+1=k y$. Then $k(y-x)=3=1 \cdot 3$. Hence $k=1$. Therefore labels of $v_{i 9}$ and $v_{i 10}$ are relatively prime.

- By applying Lemma 2.2, we obtain $\operatorname{gcd}\left(f\left(v_{i 10}\right), f\left(v_{i 11}\right)\right)=\operatorname{gcd}(12 i+1,12 i-1)=1$.

- Last, suppose that $\operatorname{gcd}\left(f\left(v_{i 1}\right), f\left(v_{i 11}\right)\right)=\operatorname{gcd}(12 i-$ $10,12 i-1)=k$. We know that $12 i-10$ is even, and $12 i-1$ is odd, but both of them are in $2(\bmod 3)$. So, $k \neq 3$. Suppose $12 i-10=k x$ and $12 i-1=k y$. Then $k(y-x)=9=1 \cdot 9$. Since neither $12 i-10$ nor $12 i-1$ is not in $0(\bmod 9)$, then it must be $k=1$. Thus $f\left(v_{i 1}\right)$ and $f\left(v_{i 11}\right)$ are relatively prime, that is $\operatorname{gcd}(12 i-10,12 i-1)=1$.

Due to any two adjacent vertices having the relatively prime labels, the function $f$ is a minimum coprime labeling with the largest label being $\operatorname{pr}\left(\operatorname{Amal}\left(W_{11}, v_{0}, t\right)\right)=12 t+1$.

For an illustration, a coprime labeling for amalgamation of 3 copies of $W_{11}$ can be seen in Figure 4.

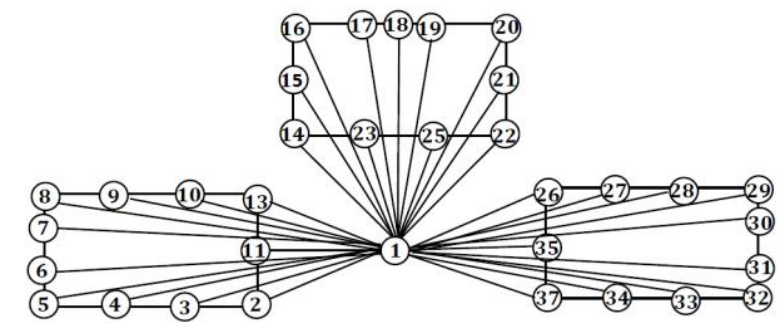

Figure 4. A coprime labeling of $\operatorname{Amal}\left(W_{11}, v_{0}, 3\right)$

\section{CONCLUDING REMARKS}

We conclude this paper by providing several open questions regarding minimum coprime numbers.

Question 1. Let $v_{0}$ be the vertex of degree 7 in $W_{7}$. Can the minimum coprime labeling be defined for amalgamation of wheel $W_{7}, \operatorname{Amal}\left(W_{7}, v_{0}, t\right)$, for any positive integer $t$ ?

Question 2. Let $v_{0}$ be the vertex of degree $n$ in $W_{n}$, and $t$ be a positive integer. Can the minimum coprime labeling be defined generally for amalgamation of odd wheel $W_{n}, \operatorname{Amal}\left(W_{n}, v_{0}, t\right)$ when $n=3(\bmod 4)$ ?

Question 3. Can the minimum coprime number be determined for amalgamation of complete graph, $\operatorname{Amal}\left(K_{n}, v, t\right)$ ? 


\section{ACKNOWLEDGMENT}

The authors are thankful to support funding from the Faculty of Mathematics and Natural Sciences, Universitas Jember. The authors also are thankful to the anonymous referee for valuable comments and kind suggestions.

\section{REFERENCES}

[1] A.H. Berliner, J. Hook, A. Mbirika, N. Dean, A. Marr, and C.D. McBee, Coprime and prime labelings of graphs, Journal of Integer Sequence 19, 2016, pp. 1-14.

[2] A. Tout, A.N. Dabboucy, and K. Howalla, Prime labeling of graphs, Nat. Acad. Sci. Letters 11, 1982, pp. 365-368.

[3] H.L Fu and K.C Huang. On prime labelings, Discrete Math. 127, 1994, pp. 181-186.

[4] H. Salmasian, A result on prime labelings of trees, Bull. Inst. Combin. Appl., 28, 2000, pp. 36-38.

[5] O. Pikhurko, Trees are almost prime, Discrete Math., 307, 2007, pp. 1455-1462.

[6] L. Robertson and B. Small, On Newman's conjecture and prime trees, Integers: The Elect. J. Combin. Number Theory 9, 2009, A10, pp. 112-128.

[7] P. Haxell, O. Pikhurko, and A. Taraz, Primality of trees, J. Combinatorics 2, 2011, pp. 481-500. DOI : https://dx.doi.org/10.4310/JOC.2011.v2.n4.a1

[8] T. Deretsky, S. M. Lee, and J. Mitchem, On vertex prime labelings of graphs, in Graph Theory, Combinatorics and Applications Vol. 1, J. Alavi, G. Chartrand, O. Oellerman, and A. Schwenk, eds., Proceedings 6th International Conference Theory and applications of graphs, Wiley, New York, 1991, pp. 359-369.

[9] S.M. Lee, I. Wui and J. Yeh, On the amalgamation of prime graphs, Bull. Malaysian Math. Soc. (Second Series), 11, 1988, pp. 59-67.
[10] M.A. Seoud, A.T. Diab, and E.A. Elsahawi, On strongly-C harmonious, relatively prime, odd graceful and cordial graphs, Proc. Math. Phys. Soc. Egypt, no. 73, 1998, pp. 33-55.

[11] D.M.T.B. Dissanayake, R.A.S.T. Abeysekara, K.D.E. Dhananjaya, A.A.I. Perera, and P.G.R.S. Ranasinghe, Prime labeling of complete tripartite graphs of the form $K_{1, m, n}$, Elicxir Journal 130, 2019, pp. 53092-53094.

[12] E. Ghorbani. and S. Kamali. Prime labeling of ladders, Journal of integer sequence, 2019.

[13] A.V. Kanetkar, Prime labeling of grids, AKCE Internat. J. Graphs Combin. 1, 2009, pp. 135-142. DOI : https://doi.org/10.1080/09728600.12088880

[14] S.K. Vaidya and K.K. Kanani, Prime labeling for some cycle related graphs, Journal of Mathematics Research 2(2), 2010, pp. 98-103.

[15] S. Ashokkumar and S. Maragathavalli, Prime labeling of some special graphs, Journal of Mathematics 11, 2015, pp. 1-5.

[16] U. M. Prajapati1 and S. J. Gajjar. Prime labeling of generalized Petersen graph, International Journal of Mathematics and Soft Computing 5(1), 2015, pp. 65-71.

[17] J.A. Gallian, A dynamic survey of graph labelling, The Electron. J. Combin., 2017, \#DS6.

[18]J.Asplund and N.B. Fox, Minimum coprime labelings for operations on graphs, Journal of Integer Sequence 17, 2017, pp. 1-20.

[19] J.Asplund and N.B. Fox. Minimum coprime labelings of generalized Petersen and prism graphs, Journal of Integer Sequence 19, 2019, pp. 1-17.

[20] C. Lee, Minimum coprime graphs, Journal of Integer Sequence 20, 2020, pp. 1-11.

[21] Sukirman, Teori Bilangan (in Indonesian), ISBN 9786023920471, Tangerang Selatan: Universitas Terbuka, 2016. 